Int. J. Plant Sci. 160(6 Suppl.):S147-S155. 1999.

(C) 1999 by The University of Chicago. All rights reserved.

1058-5893/1999/16006S-0012\$03.00

\title{
CHARACTERIZATION OF BRANCH COMPLEXITY BY FRACTAL ANALYSES
}

\author{
C. L. Alados, ${ }^{* 1}$ J. Escos, ${ }^{*}$ J. M. Emlen, $t^{+2}$ and D. C. Freeman $\neq^{3}$ \\ *Instituto Pirenaico de Ecología, Avda. Montañana 177, Apd. 202, 50080 Zaragoza, Spain; +Biological Resource Division, \\ U.S. Geological Survey, 6505 NE 65th Street, Seattle, Washington 98115, U.S.A.; ¥Department of \\ Biological Sciences, Wayne State University, Detroit, Michigan 84408, U.S.A.
}

\begin{abstract}
The comparison between complexity in the sense of space occupancy (box-counting fractal dimension $D_{c}$ and information dimension $D_{\mathrm{I}}$ ) and heterogeneity in the sense of space distribution (average evenness index $\bar{J}$ and evenness variation coefficient $J_{\mathrm{CV}}$ ) were investigated in mathematical fractal objects and natural branch structures. In general, increased fractal dimension was paired with low heterogeneity. Comparisons between branch architecture in Anthyllis cytisoides under different slope exposure and grazing impact revealed that branches were more complex and more homogeneously distributed for plants on northern exposures than southern, while grazing had no impact during a wet year. Developmental instability was also investigated by the statistical noise of the allometric relation between internode length and node order. In conclusion, our study demonstrated that fractal dimension of branch structure can be used to analyze the structural organization of plants, especially if we consider not only fractal dimension but also shoot distribution within the canopy (lacunarity). These indexes together with developmental instability analyses are good indicators of growth responses to the environment.
\end{abstract}

Keywords: developmental stability, fractal dimension.

\section{Introduction}

The symmetry of plant structures is generally associated with translations, rotations, and reflections. Another form of symmetry is that of scale invariance. Scale invariance, i.e., invariant form at different spatial scales (Schroeder 1991), is known as "self-similarity" and can be characterized (in part) by fractal dimension, i.e., the embedding dimension of the object with nonuniform density. Fractal dimension can be considered an extension of the conventional Euclidean dimension, where the exponent is the integer dimension, i.e., surface $=$ length $^{2}$ or volume $=$ length ${ }^{3}$. Fractal objects change in a noninteger way when the unit of measurement changes: thus, a nonuniform object in a two-dimensional space, as, for example, a branch with a fractal dimension between 1 and 2 . Self-similar structures abound in nature. A tree composed of branches of proportional diameter and similar angles appears to remain constant regardless of the scale of observation. Natural objects are traditionally measured in terms of Euclidean units, length, area, or volume. However, most natural objects consist of irregular lines, surfaces, or volumes full of gaps and cavities. Fractal geometry is a mathematical tool that can be used to describe such complex systems and can be applied usefully in situations where Euclidean descriptors are inappropriate. For example, the length of any structure depends on the length of the ruler with which it is measured, a fact with important implications in ecology. The distance between two points on

\footnotetext{
${ }^{1}$ Author for correspondence; e-mail alados@ipe.csic.es.

2 E-mail john_emlen@usgs.gov.

${ }^{3}$ E-mail cfreeman@sun.science.wayne.edu.
}

Manuscript received March 1999; revised manuscript received July 1999. a shrub, for instance, is not the same for a crawling insect as it is for a browsing goat; the insect must move up and down each branch while the goat can move directly from one branch to another. The volume of the tree's crown is not equivalent to the three-dimensional space in which it resides. If we want to know that volume, we must consider the complex spacing between leaves and branches. Fractal dimension is a measure of the degree to which space is filled. Thus, a tree with a dimension of, say, 2.8 fills the three-dimensional space in which it resides more fully than one with a dimension of 2.6. The significance in this case is that higher dimension means a greater capacity for interchange of matter and energy between tree and environment. To visualize this, picture two root systems: in one of them, each branch splits into two branches of somewhat shorter lengths; in the other, each branch splits three ways. The latter, which has higher fractal dimension, clearly fills up the space more completely and so has greater access to nooks and crannies where nutrients may lie.

Fractal dimension analysis is highly worthy of investigation by the morphometrist, especially when fine textural features such as roughness are concerned. The application of fractal dimension, as a quantitative measure of complexity and scaling properties and as a classification criterion for plant types, appears to be useful. It may have wide applicability to plant ecology, given that the increase in surface area in the fractal shape of branch structure results in optimal nutritional support of the involved tissue or surface area for absorption (Sugihara and May 1990; Eghball et al. 1993; Chen et al. 1994; Shibusawa 1994).

Because fractals have seen increased applications in biology over the past $10 \mathrm{yr}$, it is important to point out, before proceeding, that biologists use the term somewhat loosely. True fractals, from the mathematician's perspective, describe exact 
geometrical structure over an infinite number of scales; biologists are concerned with fractal-like objects that are statistically self-similar over a limited range of scales (Morse et al. 1985; Tatsumi et al. 1989; Fitter and Stickland 1992; Eghball et al. 1993; Alados et al. 1994; Berntson 1994; Corbit and Garbary 1995; Escós et al. 1995, 1997). Shibusawa (1994) developed a growth model of the maize root system using an L-system technique, which describes the recursive nature of branch formation using a set of iterative recursive rules (Lindenmayer 1968; Lindenmayer and Rozenberg 1976).

Before conventional fractal analysis can be used as a tool in the ecological sciences, many of the technical problems associated with the methodology must be addressed. In this study, we compared fractal dimension obtained using two different methods (box counting and information dimension) applied to a two-dimensional projection of branch architecture. To gain insight into the underlying determinants of branch fractal architecture, we investigated the effects of two environmental factors on the fractal dimension of a Mediterranean shrub, Anthyllis cytisoides L.

\section{Methods}

\section{Characterization of Fractal Architecture}

There is no single method for determining the fractal dimension of structures (see Mandelbrot 1982; Schroeder 1991; Bassingthaighte et al. 1994). But among the many ways to calculate it, there are two relevant approaches, one that depends on metric properties and one that depends on probabilistic properties (Farmer et al. 1983).

The Capacity Dimension. The capacity dimension, $D_{c}$, may be viewed as a simplified version of the Hausdorff dimension (Hausdorff 1919) and consists of calculating the minimum number of $n$-dimensional cubes of side $\varepsilon$ needed to cover the object. It is given by

$$
D_{c}=\lim _{\varepsilon \rightarrow 0}\left[\ln N_{(\varepsilon)} / \ln (1 / \varepsilon)\right]
$$

where $N_{(\varepsilon)}$ is the number of occupied cubes of side $\varepsilon$.

The box-counting method is the standard method for determining capacity fractal dimension and can be used to detect changes in the complexity of plant architecture. Box counting consists of superimposing a grid on the structure to be described and determining the number of squares that are needed to cover it (Sugihara and May 1990). The process is repeated several times with finer and finer grid sizes until the grid scale approaches pixel size (Bunde and Havlin 1994). This method has some problems. Thus, real objects are only self-similar over a limited range of scales. To avoid consequent biases, Berntson and Stoll (1997) developed the "finite-scale-corrected-dimension" (FSCD) technique, which consists of estimating $D_{c}$ only over the statistically identified region of self-similarity. Testing the curvilinearity of residuals, they identify the region of selfsimilarity. In our case we plotted the log of occupied pixels versus the log of box size and observed the linearity of the relation. The best fit with the maximum number of points was obtained just by removing the extremely small boxes of one and two pixels per side.

The Information Dimension. The information dimension, $D_{\mathrm{I}}$, is, according to Farmer et al. (1983), the superior measure to the usual box-counting dimension, $D_{c}$, so long as it is not sensitive to miscounting extremely low probability boxes and does not consider all boxes as representing the same amount of occupancy. The information dimension is a generalization of the capacity dimension that takes into account the relative probability of the cubes used to cover the set (Farmer et al. 1983). Mathematically it is defined as

$$
D_{\mathrm{I}}=\lim _{\varepsilon \rightarrow 0}\left[I_{(\varepsilon)} / \ln (1 / \varepsilon)\right]
$$

where $I_{(\varepsilon)}=-\sum_{i=1}^{N_{(\varepsilon)}} p_{i} \ln p_{i}$ and $p_{i}=x_{i} / \Sigma x_{i}: x_{i}$ is the number of occupied pixels for each box of size $i$. When all the cubes have equal probability, $p_{i}=1 / N_{(\varepsilon)}, I_{(\varepsilon)}=\ln N_{(\varepsilon)}$, and $D_{c}=D_{\mathrm{I}}$, but in general $D_{\mathrm{c}}<D_{\mathrm{I}}, I_{(\varepsilon)}$ is the amount of information necessary to characterize the state of the system within an accuracy of $\varepsilon$. It is also called the Shannon index $(H)$ and is a general expression for statistical entropy, a measure of the complexity of a system (Shannon 1948). Here we use the same grid as for box counting, but instead of determining the number of occupied squares, we count the number of occupied pixels in each box and calculate $I_{(\varepsilon)}$ for each box size. The process is repeated several times with finer and finer grid size. Then $I_{(\varepsilon)}$ is plotted against the log of the box size. The slope of this line gives $D_{\mathrm{I}}$.

The difference between the entropy maximum $\left(\ln N_{(\varepsilon)}\right)$ and the observed entropy $\left(\sum_{i=1}^{N_{(\varepsilon)}} p_{i} \ln p_{i}\right)$ is a measure both of the organization of a system and its constraints. The entropy is a measure of realized diversity or complexity. The evenness index $\left(J_{\varepsilon}\right)$ measures the heterogeneity of the structure, and it is the ratio of the observed entropy to the entropy maximum:

$$
J_{\varepsilon}=\frac{\sum_{i=1}^{N_{\varepsilon}} p_{i} \ln p_{i}}{\ln N_{\varepsilon}} .
$$

In order to discriminate among objects that have the same fractal dimension but appear different, we can measure the heterogeneity of a fractal structure and calculate its lacunarity, i.e., the degree of structural variation within the object. A procedure of calculating the lacunarity has been advanced by Bassingthwaighte et al. (1994). It consists of calculating the average variation coefficient of some measure, e.g, number of pixels in a box of given size over all scales (box sizes).

The average of the evenness index for box size ranging between eight pixels per side (16,384-box grid) and 256 pixels per side (16-box grid) is a measure of the heterogeneity of the structure similar to the lacunarity measured by Smith et al. (1996). In addition, the coefficient of variation of the evenness index $\left(J_{\mathrm{CV}}\right)$ is also a measure of heterogeneity.

In order to check the accuracy of the fractal dimension, we calculated those values for two deterministic images generated according to mathematical algorithms: the Sierpinski carpet, which has a $D_{c}$ equal to $\log 3 / \log 2$ generated from the mathematical algorithm (Bunde and Havlin 1994), and the 


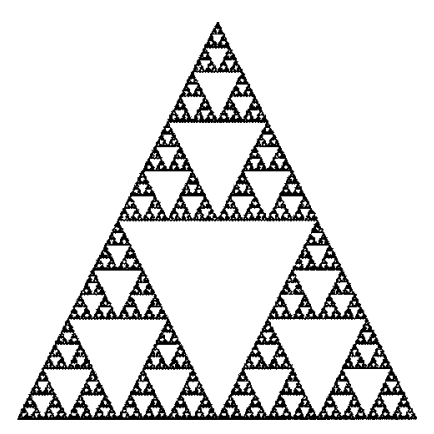

$\mathbf{J}=\mathbf{0 . 8 0 0}$

$\mathrm{J}_{\mathrm{CV}}=\mathbf{0 . 0 2 4}$
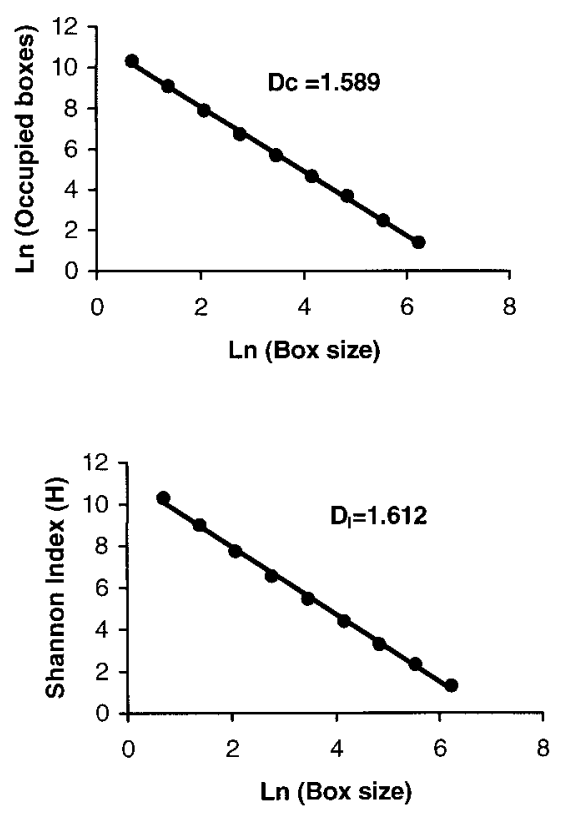

Sierpinski carpet

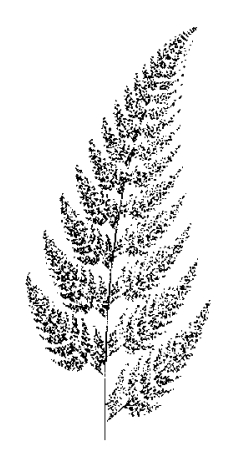

$\overline{\mathbf{J}}=\mathbf{0 . 6 9 0}$

$\mathrm{J}_{\mathrm{CV}}=\mathbf{0 . 0 9 4}$
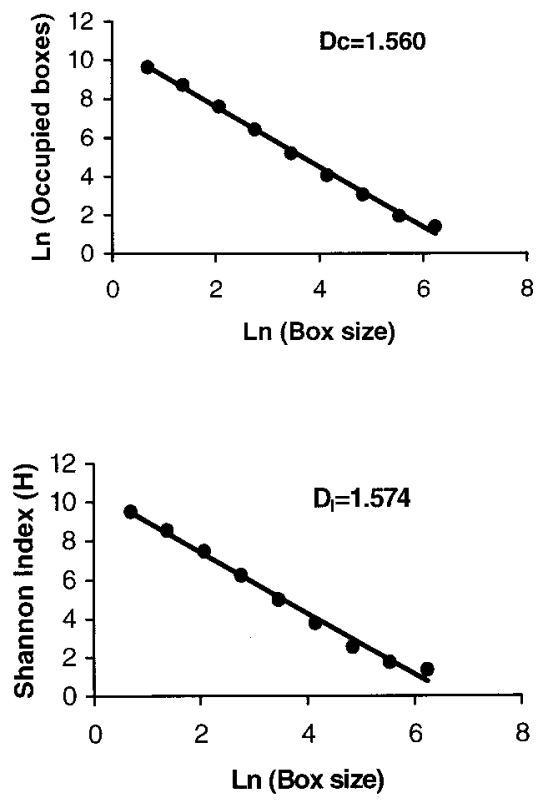

Fern leaf

Fig. 1 Sierpinski carpet and fern leaf images and log-log plots used to calculate box-counting fractal dimension (upper) and information fractal dimension (lower). Averaged evenness index and its corresponding variation coefficient are indicated in the figure.

fern leaf. These images were developed by Alain Schauber from the College of Sciences and Engineering, University of Texas, San Antonio, and were obtained from http:// www.math.utsa.edu/mirrors/maple.

\section{Fractal Analysis of Anthyllis cytisoides Branching Structure}

Anthyllis cytisoides is a western Mediterranean, endemic, leguminous shrub that lives in nearly monospecific patches in Rambla Honda valley, located in Los Filabres range (Almería, Spain), lat. $37^{\circ} 08^{\prime} \mathrm{N}$, long. $2^{\circ} 22^{\prime} \mathrm{W}$ and $600-900 \mathrm{~m}$ altitude.
Previous studies of this species have revealed that moderate natural grazing by livestock (sheep and goats), while promoting growth, also enhances homeostasis of vegetative structures and increased branch complexity, i.e., fractal dimension (Escós et al. 1997). In this study, we sought to determine whether measures of fractal complexity could detect differences associated with grazing. We compared branching fractal complexity of north- and south-exposed plants under two grazing treatments. We selected two similar plots with two consecutive alluvial fans each, which only differ in grazing treatment. One of these plots, of ca. 14 ha, had been excluded from grazing 
since September 1, 1991, while the other was grazed extensively with approximately one individual per hectare. Plants were collected from north- and south-facing slopes on the same alluvial fan in 1997. A total of 148 plants, 68 north exposed and 80 south exposed, similar in size, were sampled during March-April 1997. We chose adult plants of similar size in order to reduce variability in the analysis. Given that each plant is affected by the immediate surrounding area, each individual plant is considered to be one replicate. In order that a randomized branch sampling could be performed, the crown was divided into strata of similar size based on relative height and orientation, and one well-developed lateral branch was randomly selected from one specific stratum. From each individual plant, we cut one 3-yr-old branch. In addition, we selected a developed annual shoot from each branch located in the second or third position from the previous year's stem (numbered from the branch apex). In order to avoid grazing interference, only undamaged stems were selected. A total of 65 branches were oven dried at $70^{\circ} \mathrm{C}$ for $48 \mathrm{~h}$ and weighed with a precision balance. To obtain the fractal dimension of the branch, we made photographic slides of each 3-yr-old branch. Slides were taken from the same distance, focusing on the center of the branch. Later, slides were digitized with Kodachrome. Images were captured with Photoshop 4.0 with a resolution of $3072 \times 2048$ pixels. Because the thickness of the lines within digitized images can have a large impact on fractal dimension (Berntson 1994), images were preprocessed similarly, selecting a window size of $1024 \times 1024$ pixels, then filtering, converting to gray scale, and adjusting to the same intensity.

\section{Plant Allometry}

The relation between internode length and node order follows a self-similar sequence, where internode length declines distally. From a randomly selected shoot per branch, we measured internode length (distance between point of leaf insertions) from bottom to top with an electronic caliper, recording to the nearest $0.01 \mathrm{~mm}$. Then we examined the allometric relationship between the internode length $(L)$ and the node order (N) (Alados et al. 1994, 1998a,1998b; Escós et al. 1995, 1997). The relation, starting from the shoot base, fits the general equation

$$
L=k N^{b} e^{-a N},
$$

where $e$ is the natural base, and $k, a$, and $b$ are fitted constants. The constants of the equation were obtained using a regression analysis. The parameter $b$ represents the scaling in internode length with order. The accuracy of the curve fitting was evaluated also using the coefficient of determination, $R^{2}$, the standard error of the regression $S_{y x}$, and the standard error of the parameter $b\left(S_{b}\right)$, all of which are good estimators of homeostasis disruption. Larger values of $1-R^{2}, S_{y x}$, and $S_{b}$ are indicators of less stability. They also can be used to detect random intraindividual variability during development (Freeman et al. 1993; Graham et al. 1993; Alados et al. 1994, 1998a, 1998b; Escós et al. 1995, 1997; Sherry and Lord 1996; Anne et al. 1998). Because the number of internodes varies among shoots, we used $R^{2}$ adjusted to the degrees of freedom. The standard error of the parameter $b, S_{b}$, is positively cor-
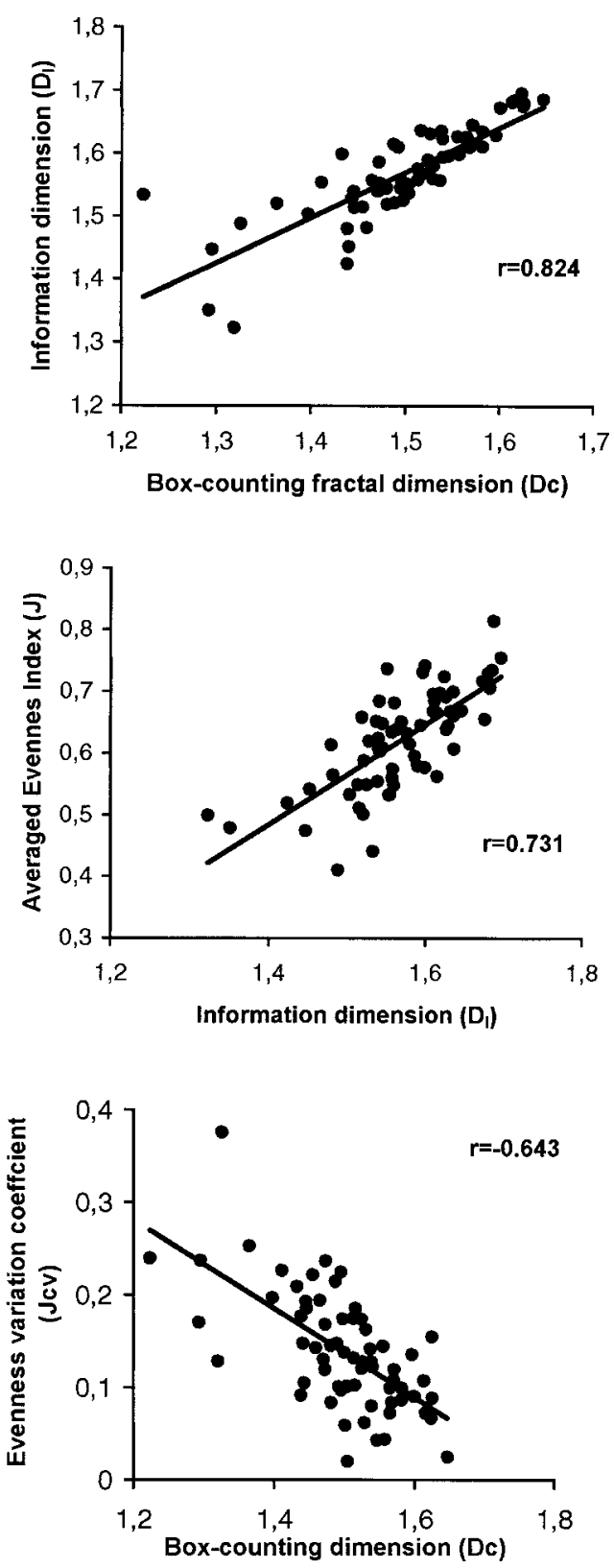

Fig. 2 Scatter plots of the relation between fractal dimension $\left(D_{c}\right.$, $D_{\mathrm{I}}$ ), averaged evenness index, and evenness coefficient of variation for the branches of the sampled Anthyllis cytisoides population.

related with $b$ (Pearson correlation coefficient $r=0.43, P<$ 0.001 ); consequently, we used $S_{b} / b$ to avoid bias as a result of the relation between treatment effects and size. Finally, because $S_{y x}$ is related to the average internode length, $S_{y x}$, following Zar's (1984) recommendations, was divided by $\bar{y}$ mean, $S_{y x} / \bar{y}$. The curve-fitting accuracy measures the extent to which the actual phenotype departs from the hypothetical, undisturbed one, during the development. 


\section{Table 1}

Two-Way ANOVA with Grazing and Exposure as Fixed Effect Factors for $D_{c}, D_{1}, \bar{J}$, and $J_{\mathrm{CV}}$

\begin{tabular}{cclccc}
\hline & & \multicolumn{4}{c}{$\mathrm{F}$} \\
\cline { 3 - 6 } \multicolumn{1}{c}{ Source } & \multicolumn{1}{c}{$\mathrm{df}$} & \multicolumn{1}{c}{$D_{\mathrm{c}}$} & \multicolumn{1}{c}{$D_{\mathrm{I}}$} & $\bar{J}$ & $J_{\mathrm{CV}}$ \\
\hline Grazing $\ldots . . . .$. & $(1,61)$ & 0.48 & 0.46 & 0.04 & 0.02 \\
Exposure $\ldots . . . .$. & $(1,61)$ & $9.70^{* *}$ & $4.96^{*}$ & $12.18^{* *}$ & $9.14^{* *}$ \\
Interaction $\ldots . .$. & $(1,61)$ & 0.31 & 1.36 & 0.24 & 0.11 \\
\hline
\end{tabular}

Note. Dependent variables are box-counting fractal dimension $D_{0}$ information dimension $D_{\mathrm{I}}$, average evenness index $\bar{J}$, and evenness index variation coefficient $J_{\mathrm{CV}}$ for Anthyllis cytisoides population. Cells with no asterisks, $P>0.05$.

${ }^{*} P<0.05$.

${ }^{* *} P<0.01$

\section{Results}

\section{Fractal Analysis of Deterministic Images}

Figure 1 presents the capacity fractal dimension $\left(D_{c}\right)$ and the information dimension $D_{\text {I }}$ for two deterministic images generated according to mathematical algorithms. Note that the Sierpinski carpet has a $D_{c}$ similar to the $\log 3 / \log 2$ generated from the mathematical algorithm (Bunde and Havlin 1994), while $D_{\mathrm{I}}$ is greater because, in dealing with digitized images, one deals not only the mathematical algorithm but also the line thickness and the digitizing processes. The same trend is observed in the second example, the fern leaf.

Two objects may have similar fractal dimension but have different structure. In order to discriminate between objects with similar fractal dimension but different space distribution, we calculated the heterogeneity of the structure. Here, the two objects look quite different. Thus, the average evenness index $(\bar{J})$ is larger for the more uniform Sierpinski carpet $(0.800)$, which also presents a lower coefficient of variation $J_{\mathrm{CV}}(0.024)$, than the more heterogeneous fern leaf $\left(\bar{J}=0.69, J_{\mathrm{CV}}=0.094\right)$.

\section{Fractal Analysis of Anthyllis cytisoides Branches}

When fractal dimension $\left(D_{\mathrm{c}}\right)$ was plotted against $D_{\text {I }}$ over the entire $A$. cytisoides sampling population, we found a high positive Pearson correlation coefficient of 0.824 (fig. 2). This relation is more pronounced for large fractal dimensions and declines when fractal complexity is low. In addition, the high correlation observed between $D_{c}$ and $\bar{J}(0.862)$ and between $D_{\text {I }}$ and $\bar{J}(0.731)$, suggests that, when branch structure is more complex in the sense of space occupancy, shoots are distributed more homogeneously throughout the plant's crown. At the same time, when $D_{c}$ declines, the evenness index variation coefficient increases (Pearson correlation coefficient $r=-0.643$ ). All the Pearson correlation coefficients were statistically significant at the 0.001 level for the 65 cases analyzed.

In order to characterize the fractal patterns of A. cytisoides architecture under different environmental conditions, we used different fractal analytical methods (tables 1 and 2). The results show a significant effect of slope exposure on $D_{\mathrm{c}}$ and $D_{\mathrm{I}}$. Branch occupancy was greater for plants on northern exposures. These plants had greater dry weight $(6.66 \pm 0.56 \mathrm{~g}$, $n=29)$ than plants from southern exposures $(4.68 \pm 049 \mathrm{~g}$, $\left.n=36, F_{1,61}=7.05, P=0.01\right)$. However this measure says nothing about the distribution of shoots within the branch. In order to know whether shoots are homogeneously distributed, we analyzed the average evenness index $(\bar{J})$. It was greater for plants from northern exposures, meaning that south-exposed plants have more pronounced gaps in the crowns and branches are heterogeneously distributed. The coefficient of variation of $J_{\varepsilon}$ may also be considered a measurement of lacunarity. This coefficient was significantly greater in the south-exposed plants, also indicating their more heterogeneous structure (tables 1 and 2; fig. 3). Conversely, no effect of grazing was observed on $D_{c}, D_{\mathrm{I}}, \bar{J}$, and $J_{\mathrm{CV}}$.

Finally, the allometric parameter $b$ differs significantly with exposure and with grazing pressure (tables 3 and 4). This parameter increased significantly with grazing $(2.38 \pm 0.06$, $n=80$, for grazed; $2.12 \pm 0.06, n=68$, for ungrazed plants). We also observed a significant difference in parameter $b$ between north- and south-exposed plants $(\bar{X} \pm$ SE are $2.47 \pm$ $0.06, n=80$ for south-exposed plants; $2.03 \pm 0.06, n=68$, for north-exposed plants). Specifically, the increase in internode length with order was larger in south-exposed plants. However, the total number of internodes produced declined in south-exposed plants $(17.08 \pm 0.57, n=80$ for south-exposed plants; $21.50 \pm 0.62, n=68$ for north-exposed plants; $\left.F_{1,144}=27.59, P<0.001\right)$. Thus, shoot length was significantly larger $\left(F_{1,144}=16.90, P<0.001\right)$ in north-exposed plants $(26.06 \pm 0.9 \mathrm{~cm}, n=68)$, than in south-exposed plants $(21.11 \pm 0.8 \mathrm{~cm}, n=80)$.

Curve-fitting accuracy of the relation between internode

Table 2

Means \pm SE Values of Dependent Variables $\left(D_{\mathrm{c}}, D_{1}, \bar{J}\right.$, and $\left.J_{\mathrm{cv}}\right)$ for Each Treatment Effect

\begin{tabular}{lccccc}
\hline & \multicolumn{2}{c}{ Ungrazed } & & \multicolumn{2}{c}{ Grazed } \\
\cline { 2 - 3 } \cline { 5 - 6 } & $\begin{array}{c}\text { North } \\
(n=11)\end{array}$ & $\begin{array}{c}\text { South } \\
(n=18)\end{array}$ & & $\begin{array}{c}\text { North } \\
(n=18)\end{array}$ & $\begin{array}{c}\text { South } \\
(n=18)\end{array}$ \\
\hline$D_{\mathrm{c}} \ldots \ldots$. & $1.531 \pm 0.02$ & $1.456 \pm 0.02$ & & $1.534 \pm 0.02$ & $1.482 \pm 0.02$ \\
$D_{\mathrm{I}} \ldots \ldots$. & $1.595 \pm 0.02$ & $1.533 \pm 0.02$ & & $1.586 \pm 0.02$ & $1.567 \pm 0.02$ \\
$\bar{J} \ldots \ldots$. & $0.662 \pm 0.02$ & $0.584 \pm 0.01$ & & $0.656 \pm 0.02$ & $0.598 \pm 0.02$ \\
$J_{\mathrm{CV}} \ldots \ldots$. & $0.109 \pm 0.02$ & $0.161 \pm 0.01$ & & $0.116 \pm 0.01$ & $0.157 \pm 0.01$ \\
\hline
\end{tabular}

Note. Dependent variables are allometric parameter box-counting fractal dimension $D_{c}$, information dimension $D_{\mathrm{I}}$, average evenness index $\bar{J}$, and evenness index variation coefficient $J_{\mathrm{CV}}$ for Anthyllis cytisoides population. 


\section{Anthyllis cytisoides}

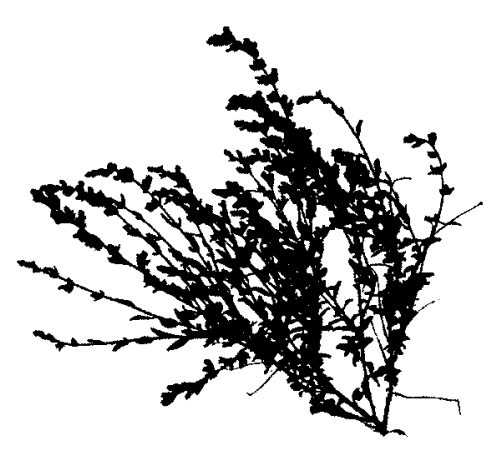

$\overline{\mathbf{J}}=\mathbf{0 . 7 5 5}$

$\mathbf{J}_{\mathrm{CV}}=\mathbf{0 . 0 6 7}$
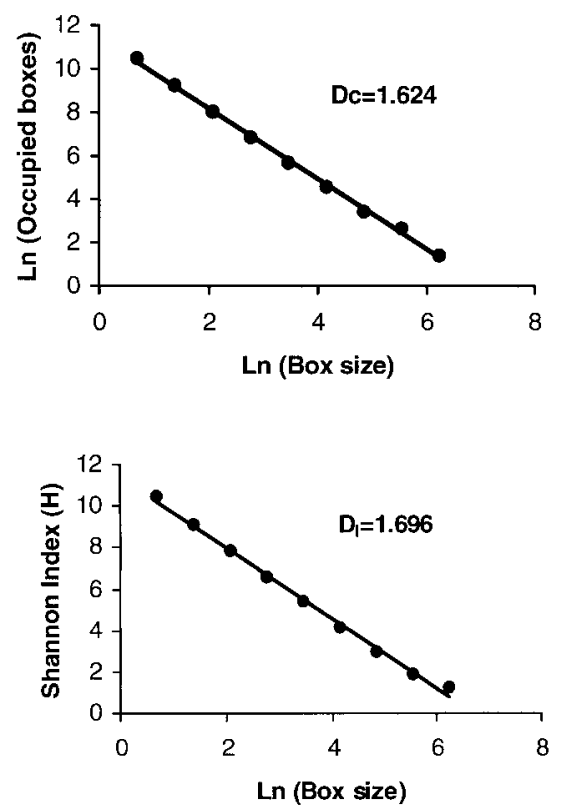

Grazed North-Exposed

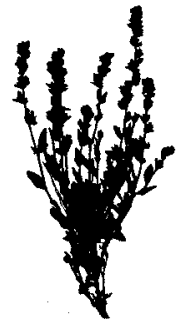

$\overline{\mathrm{J}}=\mathbf{0 . 6 0 7}$

$\mathrm{J}_{\mathrm{CV}}=\mathbf{0 . 1 1 9}$
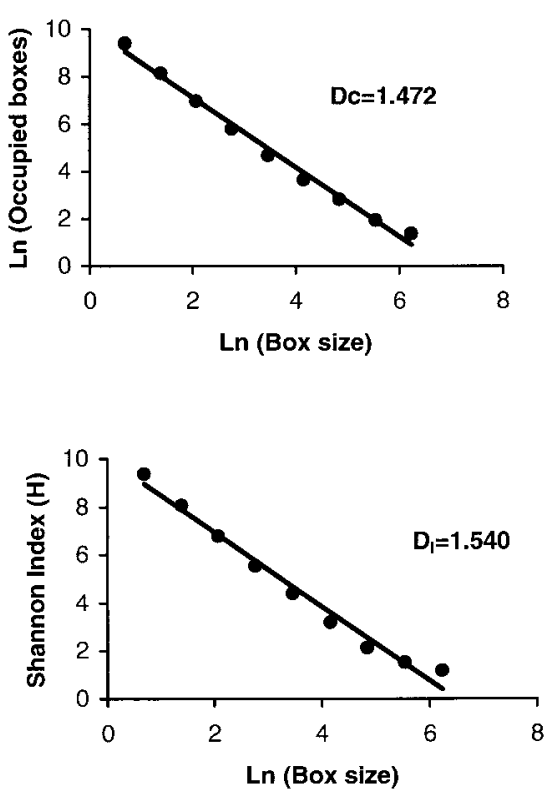

Ungrazed South-Exposed

Fig. 3 Two morphologically distinct branch images coming from one grazed north-exposed plant and one ungrazed south-exposed plant. Log-log plots used to calculate box-counting fractal dimension (upper) and information fractal dimension (lower). Averaged evenness index and its corresponding variation coefficient are indicated in the figure.

length and node order for each treatment effect is presented in tables 3 and 4 . The adjusted coefficient of determination, $R^{2}$, standard error of the regression, $S_{y x} / \bar{y}$, and the standard error of the slope, $S_{b} / b$, were significantly affected by grazing, indicating that A. cytisoides was developmentally more stable when grazed (tables 3 and 4). Grazed plants are developmentally more stable both on north and south slopes as indicated by the larger $R^{2}(0.79 \pm 0.02$ for 80 grazed and $0.69 \pm$
0.02 for 68 ungrazed plants) and lower $S_{y x} / \bar{y}(0.17 \pm 0.01$ vs. $0.20 \pm 0.01)$ and $S_{b} / b(0.13 \pm 0.01$ vs. $0.17 \pm 0.01)$. Conversely, exposure did not affect the developmental instability of A. cytisoides in 1997.

\section{Discussion}

In this study, we compared fractal dimension obtained using two different methods (box counting and information 
Table 3

Two-Way ANOVA with Grazing and Exposure as Fixed Effect Factors for $b, \boldsymbol{R}^{2}, S_{y x} / \bar{y}$, and $S_{b} / b$

\begin{tabular}{ccrrrr}
\hline & & \multicolumn{4}{c}{$F$} \\
\cline { 3 - 6 } Source & df & \multicolumn{1}{c}{$b$} & \multicolumn{1}{c}{$R^{2}$} & \multicolumn{1}{c}{$S_{y x} / \bar{y}$} & $S_{b} / b$ \\
\hline Grazing $\ldots . . . . .$. & $(1,144)$ & $9.14^{*}$ & $18.20^{*}$ & $12.93^{*}$ & $9.34^{*}$ \\
Exposure ........ & $(1,144)$ & $26.46^{*}$ & 1.00 & 3.30 & 0.42 \\
Interaction ...... & $(1,144)$ & 0.09 & 0.83 & 1.49 & 1.22 \\
\hline
\end{tabular}

Note. Dependent variables are allometric parameter $b$ and curve fitting estimators (adjusted coefficient of determination, $R^{2}$, standard error of the regression, $S_{y x} / \bar{y}$, and the standard error of the slope $\left.S_{b} / b\right)$ for Anthyllis cytisoides population. Cells with no asterisks, $P>$ 0.05 .

${ }^{*} P<0.01$.

dimension) applied to two deterministic images generated from mathematical algorithms and two-dimensional projection of branch architecture in Anthyllis cytisoides. The use of two-dimensional projections to study the fractal structure of three-dimensional objects is based on the projection theorem (Marstrand 1954), which states that the fractal dimension of a projection in an $n-1$ dimensional space is equal to $D-1, n$ being the Euclidean dimension and $D$ the fractal dimension. However, because natural objects are not truly fractal, planar or linear projections may provide only approximations of the whole structure's real fractal dimension. An experimental estimation of three-dimensional fractal root systems revealed that, although the planar projection dimension differed from the dimension in three-dimensional space -1.0 , a linear relationship existed between them (Nielsen et al. 1997).

The capacity fractal dimension obtained by the box-counting method $\left(D_{c}\right)$ is closer to the fractal dimension used to generate the deterministic image than the information dimension $\left(D_{\mathrm{I}}\right)$. In addition we observed a highly significant positive correlation between the information fractal dimension $\left(D_{\mathrm{I}}\right)$ and the box-counting fractal dimension $\left(D_{c}\right)$ for A. cytisoides, especially when fractal dimensions were large. Box counting is used to detect changes in fractal architecture of plants because it is a fast measure of complexity (it can be automated using image analysis systems). For example, capacity dimension has been used to quantify root complexity in two-dimensional space (Tatsumi et al. 1989; Fitter and Stickland 1992; Eghball et al. 1993, Berntson 1994) and plant shoot systems (Morse et al. 1985; Alados et al. 1994; Corbit and Garbary 1995; Escós et al. 1995, 1997). It is currently being used as a diagnostic tool in medicine to detect histopathological lesions (Cross and Cotton 1992; Losa 1995).

The fact that it is obtained from the box-counting algorithm linear relationship, however, does not prove that the structure is fractal; a log-log linear relationship is a necessary but not a sufficient requirement for a structure to be characterized as fractal (Smith et al. 1996). Nevertheless, box counting provides an estimate of $D_{c}$ that can be used to characterize the irregularities of spatial correlations of a structure. Note that two objects may have the same fractal dimension but appear very different from one another. That is, $D_{\text {c }}$ provides no unique morphological specification (Smith et al. 1996). Thus, in application to plant architecture, the fractal capacity dimension measures the complexity without implying any underlying growing mechanisms.

More complete information about the structure is obtained when we calculate not only the complexity $\left(D_{c}\right.$ or $\left.D_{\mathrm{I}}\right)$ but also the heterogeneity of the structure $\left(\bar{J}\right.$ and $\left.J_{\mathrm{CV}}\right)$. Our study of $A$. cytisoides showed that capacity fractal dimension $\left(D_{c}\right)$ was inversely correlated with the evenness index coefficient of variation $\left(J_{\mathrm{CV}}\right)$. Thus, when branch fractal dimension increases, shoots are evenly distributed within the crown. Moreover, low complexity of branch structure is paired with increased gap formation. By analyzing information dimension, $D_{\mathrm{I}}$, and its related index $J_{\mathrm{CV}}$, one may discover not only whether there is an increase in surface area of a branch system but also whether there is even distribution within the crown. Provided the extended general use of the box-counting method, we suggest the use of both $D_{\mathrm{c}}$ and $D_{\mathrm{I}}$ to characterize branch complexity and $J_{\mathrm{CV}}$ to measure the heterogeneity of the structure.

Branching structures favor rapid and efficient transport of substances over a complex spatially distributed system (Sugihara and May 1990; Eghball et al. 1993; Chen et al. 1994; Shibusawa 1994; Goldberger 1997). Loss of fractal complexity in morphological and physiological systems parallels a reduction in efficient transport of substances and information (Bassingthwaighte et al. 1994; Goldberger 1997). This suggests that larger fractal dimension and lower heterogeneity of

Table 4

Means \pm SE Values of Dependent Variables and Parameter Equation $\left(b, R^{2}, S_{y x} / \bar{y}\right.$, and $\left.S_{b} / b\right)$ for Each Treatment Effect

\begin{tabular}{lccccc}
\hline & \multicolumn{2}{c}{ Ungrazed } & & \multicolumn{2}{c}{ Grazed } \\
\cline { 2 - 3 } \cline { 5 - 6 } & $\begin{array}{c}\text { North } \\
(n=28)\end{array}$ & $\begin{array}{c}\text { South } \\
(n=40)\end{array}$ & & $\begin{array}{c}\text { North } \\
(n=40)\end{array}$ & $\begin{array}{c}\text { South } \\
(n=40)\end{array}$ \\
\hline$b \ldots \ldots \ldots$ & $1.91 \pm 0.10$ & $2.32 \pm 0.08$ & & $2.14 \pm 0.08$ & $2.61 \pm 0.08$ \\
$R^{2} \ldots \ldots \ldots$ & $0.66 \pm 0.03$ & $0.71 \pm 0.02$ & & $0.78 \pm 0.02$ & $0.79 \pm 0.02$ \\
$S_{y x} / y \ldots \ldots$ & $0.20 \pm 0.01$ & $0.20 \pm 0.01$ & & $0.15 \pm 0.01$ & $0.18 \pm 0.01$ \\
$S_{b} / b \ldots \ldots$. & $0.18 \pm 0.02$ & $0.16 \pm 0.01$ & & $0.13 \pm 0.01$ & $0.13 \pm 0.01$ \\
\hline
\end{tabular}

Note. Dependent variables are allometric parameter $b$ and curve fitting estimators (adjusted coefficient of determination, $R^{2}$, standard error of the regression, $S_{y x} / \bar{y}$, and the standard error of the slope $S_{b} / b$ ) for Anthyllis cytisoides population. 
branching structures in plants must be related to the efficient plant interchange of gas and substances with the atmosphere.

Developmental stability is the result of a suite of processes that buffer the disruptive effect of environmental variation during development and require energy consumption (Palmer 1996). Developmental instabilities have usually been measured in the form of fluctuating asymmetry, estimated as random deviations from bilateral symmetry (Ludwig 1932; Van Valen 1962; Palmer and Strobeck 1986). However, statistical noise in allometric relations is another, and generally more reliable, stress indicator (Freeman et al. 1993; Graham et al. 1993a; Alados et al. 1994, 1998a, 1998b; Escos et al. 1995, 1997; Sherry and Lord 1996; Anne et al. 1998).

In this study, we observed that grazing affects the developmental stability of A. cytisoides. Grazed plants are developmentaly more stable than ungrazed plants. In dry-land plants, water stress is the most important limit to survival and reproduction. Under most circumstances, the evolutionary response to water deficit has been low relative growth rate and, in consequence, low nutrient requirements at the expense of reduced overall productivity (Chapin 1991). We observed that A. cytisoides plants were in better condition when they were grazed. Grazed plants had a lower water deficit and greater survival and were developmentally more stable than ungrazed plants (J. Escos, C. L. Alados, F. Pugnaire, J. Puigdefabregas, and J. Emlen, unpublished manuscript). Our results are supported by the Herbivory Optimization Hypothesis (McNaughton 1979a, 1979b; Dyer et al. 1982; Crawley 1983; Williamson et al. 1989; Alward and Joern 1993), which predicts increased plant fitness at low to moderate levels of herbivory.

On the other hand, exposure affects fractal dimension but not the developmental instability of A. cytisoides during the wet year 1997 (104.7 mm of rainfall during the spring). Northexposed plants present larger growth and higher branch complexity with even branch distribution, increasing the efficiency of gas interchange at the whole plant level. However, this re- sponse is not paired with larger developmental stability of those structures.

Previous studies in A. cytisoides found that, under moderate grazing, plants increased branch complexity, also enhancing developmental stability. However, under high grazing pressure not enough energy was available, and a reduction in developmental homeostasis and fractal complexity occurred (Escós et al. 1997). Thus, when available energy is low, growth and homeostasis may become antagonistic. By reducing growth, plants can ameliorate stress through a reduction of nutrient demands (Chapin and Kedrowski 1983; Chapin et al. 1986; Jones et al. 1991; Chapin et al. 1993), allowing the maintenance of a steady supply of nutrients for developmental stability. Unless nutrient demands can be so reduced, however, energy required to maintain homeostasis is lost, and disrupted or inconsistent development may result. This impact can be seen in the form of developmental instability. Nevertheless, the response of the plant to the environment could result in a timescaled response where impaired growth and complexity may not be a simultaneous process. The fractal dimension of branch structure can be used to analyze the structural organization of plants, especially if we consider not only fractal dimension but also shoot distribution within the canopy (lacunarity). These indices, together with developmental instability analyses, are good indicators of plant responses to the environment.

\section{Acknowledgments}

The work was supported by the Comision Interministerial de Ciencia y Tecnología (project AMB93-0777-C02-01) and the Mediterranean Desertification and Land Use (MEDALUS II) collaborative research project. MEDALUS II was funded by the European Community under its Environment Program, contract EV5V 0128. The support from both programs is gratefully acknowledged.

\section{Literature Cited}

Alados CL, JM Emlen, B Wachocki, CD Freeman 1998a Instability of development and fractal architecture in dryland plants as an index of grazing pressure. J Arid Environ 38:63-76.

Alados CL, J Escós, JM Emlen 1994 Scale asymmetry: a tool to detect developmental instability under the fractal geometry scope. Pages 25-36 in MM Novak, ed. Fractals in the natural and applied sciences. Elsevier Science, Amsterdam.

Alados CL, T Navarro, B Cabezudo, JM Emlen, CD Freeman $1998 b$ Developmental instability in gynodioecicus Teucrium lusitanicum. Evol Ecol 12:21-34.

Alward R D, A Joern 1993 Plasticity and overcompensation in grass responses to herbivory. Oecologia 95:358-364

Anne P, F Mawri, S Gladstone, DC Freeman 1998 Is fluctuating asymmetry a reliable biomonitor of stress? a test using life history parameters in soybean. Int J Plant Sci 159:559-565.

Bassingthwaighte JB, LS Liebovitch, BJ West 1994 Fractal physiology. Oxford University Press. Oxford. 364 pp.

Berntson GM 1994 Root systems and fractals: how reliable are calculations of fractal dimension? Ann Bot 73:281-284.

Berntson GM, P Stoll 1997 Correcting for finite spatial scales of selfsimilarity when calculating the fractal dimansion of real-world structures. Proc R Soc Lond B 264:1531-1537.

Bunde A, S Havlin 1994 Fractals in science. Springer, Berlin. 298 pp.
Chapin FS, K Autumn, F Pugnaire 1993 Evolution of suites of traits in response to environmental stress. Am Nat 142(suppl):S78-S92.

Chapin FS, RA Kedrowski 1983 Seasonal changes in nitrogen and phosphorus fractions and autumn retranslocation in evergreen and deciduous taiga trees. Ecology 64:376-391.

Chapin FS, PM Vitousek, KV Cleve 1986 The nature of nutrient limitation in plant communities. Am Nat 127:48-58.

Chapin FS III 1991 Effects of multiple environmental stresses on nutrient availability and use. Pages 67-88 in HA Mooney, WE Winner, EJ Pell, E Chu, eds. Response of plants to multiple stress. Academic Press, San Diego.

Chen SG, R Ceulemans, I Impens 1994 A fractal-based Populus canopy structure model for the calculation of light interception. For Ecol Manag 69:97-110.

Corbit JD, DJ Garbary 1995 Fractal dimension as a quantitative measure of complexity in plant development. Proc R Soc Lond B 262: 16.

Crawley MJ 1983 Herbivory, the dynamics of animal-plant interactions. University of California Press, Berkeley and Los Angeles.

Cross SS, DWK Cotton 1992 The fractal dimension may be a useful morphometric discriminant in histopathology. J Pathol 166: 409-411.

Dyer MI, JK Detling, DC Coleman, DW Hilbert 1982 The role of 
herbivores in grasslands. Pages 255-295 in JR Estes, RJ Tyrl, JN Bruuken, eds. Grasses and grasslands: systematics and ecology. University of Oklahoma Press, Norman.

Eghball B, JR Settimi, JW Maranville, AM Parkhurst 1993 Fractal analysis for morphological description of corn roots under nitrogen stress. Agron J 85:287-289.

Escós J, CL Alados, JM Emlen 1995 Fractal structures and fractal functions as disease indicators. Oikos 74:310-314.

1997 Grazing impact on plant fractal architecture and fitness of a Mediterranean shrub (Anthyllis cytisoides). Funct Ecol 11: 66-78.

Farmer D, E Ott, JA Yorke 1983 The dimension of chaotic attractors. Physica 7D:153-180.

Fitter AH, TR Stickland 1992 Fractal characterization of root system architecture. Funct Ecol 6:632-635.

Freeman DC, JH Graham, JM Emlen 1993 Developmental stability in plants: symmetries, stress and epigenesis. Genetica 89:97-119.

Goldberger AL 1997 Fractal variability versus pathologic periodicity: complexity loss and stereotypy in disease. Perspect Biol Med 40: 543-561.

Graham JH, DC Freeman, JM Emlen 1993 Developmental stability: a sensitive indicator of population under stress. Pages 136-158 in WG Landis, JS Hughes, MA Lewis, eds. Environmental toxicology and risk assessment. ASTM STP 1179. American Society for Testing and Materials, Philadelphia.

Hausdorff F 1919 Dimension und Auberes Mab. Math Ann 79: 157-179.

Jones JB Jr, B Wolf, HA Mills 1991 Plant analysis handbook. MicroMacro, Athens, Ga., 213pp.

Lindenmayer A 1968 Mathematical models for cellular interactions in development. J Theor Biol 18:300-315.

Lindenmayer A, G Rozenberg 1976 Automata, languages, development. North-Holland, Amsterdam.

Losa GA 1995 Fractals in pathology: are they really useful? Pathologica 87:310-317.

Mandelbrot B 1982 The fractal geometry of nature. W. H. Freeman, New York. 460 pp.

Marstrand J M 1954 Some fundamental geometric properties of plane stes of fractional dimension. Proc Lond Math Soc 4:257-302.

McNaughton S.J 1979a Grassland-herbivore dynamics. Pages 46-81 in ARE Sinclair and M Norton-Griffiths, eds. Dynamics of an ecosystem, Serengeti. University of Chicago Press, Chicago.
$1979 b$ Grazing as an optimization process: grass-ungulate relationships in the Serengeti. Am Nat 113:691-703.

Morse DR, JH Lawton, MM Dodson, MH Williamson 1985 Fractal dimension of vegetation and the distribution of arthropod body lengths. Nature 314:731-733.

Nielsen KL, JP Lynch, HN Weiss 1997 Fractal geometry of bean root systems: correlations between spatial and fractal dimension. Am J Bot 84:26-33.

Osawa A 1995 Inverse relationship of crown fractal dimension to self thinning exponent of tree populations-a hypothesis. Can J For Res 25:1608-1617.

Palmer AR 1996 Waltzing with asymmetry: is fluctuating asymmetry a powerful new tool for biologists or just a alluring new dance step? BioScience 46:518-532.

Prusinkiewicz P, A Lindenmayer, JS Hanan, FD Fracchia, DR Fowler, MJ de Boer, ML Mercer 1990 The algorithmic beauty of plants. Springer, New York.

Schroeder M 1991 Fractals, chaos, power laws. W. H. Freeman, New York. 429 pp.

Shannon C 1948 A mathematical theory of communication. Bell Tech Jour 27:379-423, 623-656.

Sherry RA, EM Lord 1996 Developmental stability in leaves of Clarkia tembloriensis (Onagraceae) as related to population outcrossing rates and heterozygosity. Evolution 50:80-91.

Shibusawa S 1994. Modeling the branching growth fractal pattern of the maize root system. Plant Soil 165:339-347.

Smith TG, GD Lange, WB Marks 1996 Fractal methods and results in cellular morphology: dimensions, lacunarity and multifractals. J Neurosci Methods 69:123-136.

Sommerer JC, E Ott 1993 Particles floating on a moving fluid: a dynamically comprehensible physical fractal. Science 259:335-339.

Sugihara G, RM May 1990 Applications of fractals in ecology. Trends Ecol Evol 5:79-86.

Tatsumi J, A Yamauchi, Y Kono 1989 Fractal analysis of plant root system. Ann Bot 64:499-503.

Tracy M, DC Freeman, JM Emlen, JH Graham, RA Hough 1995 Developmental instability as a biomonitor of environmental stress: an illustration using aquatic plants and macroalgae. Pages 313-338 in FM Butterworth, ed. Biomonitors and biomarkers as indicators of environmental change. Plenum, New York.

Williamson SC, JK Detling, JL Dodd, MI Dyer 1989 Experimental evaluation of the grazing optimization hypothesis. J Range Manag 42:149-152. 